\title{
aniki
}

Revista Portuguesa da Imagem em Movimento

Portuguese Journal of the Moving Image

\section{Música y Sonido en el Cine Chileno: Nuevas voces para viejas historias}

\author{
Martín Farías \\ University of Edinburgh \\ mefz1936@gmail.com \\ https://orcid.org/0000-0002-9464-8486
}

RESUMEN Este artículo reflexiona sobre algunos problemas metodológicos y conceptuales que surgen al momento de estudiar la música y el sonido en el cine chileno. Estos asuntos se sitúan en el contexto de una creciente digitalización de cintas y documentos que ha tenido lugar en las últimas décadas y que ha conllevado una serie de cambios en el estudio del cine. Para esto se propone un análisis de dos documentales icónicos de la historia del cine en Chile: Mimbre (Sergio Bravo, 19571959) y La batalla de Chile (Patricio Guzmán, 1975-1979). Se sostiene que el estudio de la música y el sonido permite observar fenómenos ignorados y redefinir cuestiones que hasta ahora han sido pasadas por alto en la historiografía.

PAlabRas Clave Cine chileno; música de cine; narrador; Mimbre; La batalla de Chile.

\section{No han escuchado nada aún}

Casi 100 años han pasado desde que se oyera la mítica frase "no han escuchado nada aún" en la película El cantor de jazz (The Jazz Singer, Alan Crosland, 1927) que marcó el comienzo de la era sonora en el cine. ${ }^{1}$ Si bien el estudio de filmografías como la norteamericana y la de algunos países europeos ha incorporado desde hace ya décadas los aspectos musicales y sonoros, en el cine latinoamericano estas aproximaciones continúan en un espacio más bien marginal.

Este artículo ofrece una reflexión respecto a cómo el estudio del sonido y la música en el cine chileno permite vislumbrar cuestiones que hasta

\footnotetext{
${ }^{1}$ La frase, que en su inglés original era "You ain’t heard nothin' yet" fue pronunciada por el actor Al Jolson y por su simbolismo se le ha considerado un hito en el cambio tecnológico que implicó la llegada del 3sonoro.
} 
ahora han sido prácticamente pasadas por alto en la historiografía y el análisis cinematográfico y que obligarían a redefinir ideas, fechas, periodizaciones y nociones de obras icónicas del cine latinoamericano. En la primera parte del artículo se plantea una breve discusión en torno a los desafíos de la investigación sobre cine latinoamericano en un contexto de creciente digitalización de fuentes. Posteriormente se analizan dos casos, que son Mimbre (Sergio Bravo, 1957-1959) y La batalla de Chile (Patricio Guzmán, 1975-1979). En cuanto a Mimbre se destacan dos problemas fundamentales: el año en que la película ha sido fechada y sus implicancias, así como la existencia de una locución que la película incluyó por muchos años y que luego fue descartada. Un caso similar ocurre con la La batalla de Chile cuya locución original ha sido reemplazada al menos en dos ocasiones no solo modificando el texto sino también la persona que la interpreta. Finalmente, se ofrecen algunas conclusiones en torno al análisis de estos casos considerando cómo el estudio de sus aspectos sonoros permite visibilizar cuestiones que han sido pasadas por alto en anteriores estudios. Junto con esto, se reflexiona sobre los problemas de la digitalización de fuentes y la accesibilidad a estas películas.

\section{Digitalización y acceso en tiempos convulsionados}

La creciente digitalización de fuentes para el estudio del cine latinoamericano ha contribuido enormemente a la democratización del acceso y ha permitido desarrollar investigaciones que poco tiempo atrás hubieran resultado imposibles. Sin embargo, estos cambios no están ajenos a dificultades, lo que ha suscitado una serie de reflexiones que invitan a mirar con cautela las posibilidades de lo digital. Rielle Navitski (2014) advierte algunas inquietudes teóricas y metodológicas al respecto y destaca por ejemplo las falencias del sistema OCR con que son habitualmente digitalizados documentos de texto o el aislamiento de quienes investigan debido a la posibilidad de revisar archivos en forma remota. ${ }^{2}$ En una línea similar, Andrea Cuarterolo ha sugerido que el acceso en línea a documentos requiere repensar el trabajo de archivo

\footnotetext{
${ }^{2}$ OCR por sus siglas en inglés “Optical Character Recognition" es un sistema de reconocimiento de caracteres que permite la búsqueda de palabras específicas en documentos digitalizados como periódicos o revistas.
} 
y asumir ciertas precauciones entendiendo que "toda digitalización implica una selección que tiene un inevitable componente subjetivo y deja afuera un importante volumen de documentos potencialmente útiles" $(2017,426)$. La autora añade que a pesar de las ventajas de la web que nos permiten acceder a un enorme número de películas debemos tener en cuenta que este tipo de acceso a materiales "no reemplaza la experiencia de investigación directa en los acervos" (2017, 426).

Si bien estas preocupaciones son relevantes, vale la pena tener en cuenta que toda pesquisa sobre cine latinoamericano, tal como ocurre en distintas áreas de las artes, humanidades y ciencias sociales, está mediada por condiciones materiales que muchas veces están lejos de ser ideales. Por ejemplo, un gran número de investigaciones se realizan en lugares distantes de los archivos fílmicos o bibliotecas y en esos casos la posibilidad de acceso remoto no es una alternativa sino muchas veces la única opción. A su vez, la pandemia de COVID-19 ha acentuado las dificultades de acceso a ese tipo de espacios físicos fomentando aún más el trabajo con fuentes digitales. Si bien se podría considerar que esto es un hecho fortuito y que en el futuro las cosas podrían volver a ser como antes, la investigación no se ha detenido y el impacto de la pandemia en ella es algo que todavía no podemos siquiera dimensionar.

Ahora bien, el problema de acceso a fuentes no es en ningún caso una cuestión nueva, aunque son temas que generalmente no se tocan cuando se presentan los resultados de nuestras pesquisas pues se tiende a pensar que las dificultades no sorteadas restan legitimidad a nuestros estudios. Muchas veces pareciera que las investigaciones se realizan en una suerte de contexto ideal en que fue posible acceder a todo y que las contrariedades fueron completamente resueltas cuando en la realidad todo estudio está sujeto a una infinidad de problemas que moldean el resultado del trabajo y limitan su alcance.

Si bien las sospechas ante las fuentes digitales son legítimas, con ellas se corre el riesgo de idealizar el trabajo con materiales físicos como si estos estuvieran ajenos a procesos de selección, omisiones y a los innumerables azares de cualquier archivo. Las experiencias pueden ser muy variables dependiendo de la institución y del material que nos 
interese visitar y consultar. Por ejemplo, en el caso chileno la Cineteca Nacional no conserva los negativos en celuloide de muchas cintas sino copias en Betacam, U-Matic o DVD. ${ }^{3}$ Asimismo, en las instituciones que han digitalizado y dado libre acceso a sus acervos cabe preguntarse cuán fácil resultará acceder a los materiales originales o será que la experiencia en dichos lugares se termina asemejando más a la experiencia virtual de lo que nos imaginamos. Ahora, más allá de la dicotomía entre lo físico y lo virtual, tal como plantea Ignacio Albornoz, el acceso a las obras cinematográficas continúa mediado por una serie de azarosos factores como la disposición de los mismos realizadores, sus herederos, la disponibilidad de copias en archivos y la calidad de éstas $(2020,179)$.

Junto con el tipo de copia disponible hay otras dificultades que surgen a la hora de revisar los materiales fílmicos. Por ejemplo, el modo en que se fechan las películas es en sí mismo un hecho problemático. En el caso de largometrajes de ficción que tuvieron un estreno y que éste se documentó resulta sencillo pues la fecha suele ser simplemente la de dicho evento. Pero qué pasa con los documentales, cintas experimentales o películas institucionales que no tuvieron un estreno oficial o se mostraron en eventos pequeños no documentados por la prensa. En algunos casos se recurre a la fecha de filmación como ha ocurrido con Mimbre que suele fecharse en 1957 que fue cuando su director capturó las imágenes, aunque como veremos la finalización de la película tomó bastante más tiempo. En otras ocasiones se apuesta por una fecha aproximada muchas veces sin reparar en informaciones complementarias o incluso en lo que aparece en pantalla. Dos breves casos ilustran esta situación: El derecho al descanso es un documental institucional dirigido por Adolfo Silva y producido por La Oficina de Información y Radiodifusión del gobierno de Salvador Allende para dar a conocer la implementación de los llamados Balnearios Populares. Esta iniciativa buscaba facilitar el acceso a familias de clase trabajadora para que pudieran vacacionar. La Cineteca Virtual de la Universidad de Chile la fecha en 1970 y CineChile.cl replica esa información. No obstante, algunos elementos de la película revelan que no pudo haber sido realizada ese año: se muestran los primeros Balnearios que abrieron al público en febrero de 1971 y en el minuto 06:07 se ve un

\footnotetext{
${ }^{3}$ El acervo de la Cineteca Nacional de Chile se puede consultar en el sitio https://cinetecanacional-bd.cl/.
} 
cartel anunciando un evento que tendría lugar el sábado 7 de febrero, que de acuerdo con el calendario solo puede haber sido en 1971. De modo similar, Escuela Santa María de Iquique, documental de Claudio Sapiaín sobre la matanza obrera de 1907 en el norte de Chile, es fechada en algunos sitios en 1970 y en otros incluso en 1969. Sin embargo, la música que se utiliza y en la que se habría inspirado el director para realizar la película no se grabó hasta mediados de 1970, que es la célebre Cantata Popular Santa María de Iquique de Luis Advis y Quilapayún. Ahora, una nota de prensa de julio de 1971 la ubica como uno de los documentales más recientes del momento lo que da luces que podría haberse finalizado y exhibido recién ese año (Telecran 97, 16-22 julio 1971).

Con estas constataciones no se busca desmerecer el trabajo de los archivos fílmicos que realizan una labor encomiable sino llamar la atención entre quienes investigan el cine a plantearse este tipo de preguntas y no asumir los datos de forma acrítica. Del mismo modo, más allá de precisar fechas lo que interesa es cómo estos problemas permiten interrogar la producción fílmica y los supuestos que se van estableciendo en base a las informaciones disponibles. A continuación, se presenta un caso en el que la fecha usada para datar una película trae aparejada una serie de definiciones para la historia del cine chileno.

\section{Mimbre: música experimental y narración ausente}

Mimbre es un corto documental de diez minutos acerca del trabajo de Alfredo "Manzanito" Manzano, un artesano que vivía en Santiago y creaba diversas figuras con ese material. La cinta evita completamente el tono informativo tan habitual en el documental de esos años en favor de una exploración visual en que la cámara va mostrando al artesano, su entorno de trabajo, las figuras que crea, así como a otras personas y mascotas que pasan por su taller.

Producida al alero del Centro Experimental de la Universidad de Chile que fundara Bravo, la obra es considerada un hito fundacional del cine experimental y de arte en Chile en diversos estudios (Corro et al. 2007; Cortínez y Engelbert 2014; Aravena y Pinto 2018), pues representa una propuesta radicalmente nueva en términos estéticos respecto a la 
producción fílmica hasta fines de los cincuenta en el país. Sin embargo, al estudiar esta película enfocándose en su música comienzan a aparecer algunos problemas. ${ }^{4}$

La música para Mimbre que compuso Violeta Parra hace parte de su trabajo más experimental en que utiliza elementos del folklore chileno como base para composiciones en guitarra. Son piezas que, si bien toman elementos rítmicos de géneros folklóricos como la tonada y la cueca, no siguen ni la estructura clásica ni las armonías más habituales de esos géneros, explorando en lugar de eso, el uso de disonancias, atonalidad y métricas irregulares. Al analizar el trabajo musical de la película surgen algunas interrogantes. Hay en la música pequeños fragmentos que se encuentran en otras piezas para guitarra de la cantautora. Se podría afirmar simplemente que Parra citó materiales musicales preexistentes en su música para Mimbre, pero las fechas en que se crearon dichas piezas no están del todo claras, ni tampoco la fecha en que se compuso la música de la película. En 1957, mientras Mimbre era filmada, Parra registró algunas piezas de este estilo en su EP Composiciones para guitarra lanzado a fines de ese año (Ecran 1380, 31 diciembre 1957, 30). Un fragmento de "Tres palabras", incluida en el EP, aparece en Mimbre. Parra también usó "Tres palabras" para musicalizar el poema "El pueblo" de Pablo Neruda, que grabó en 1961 en su LP Toda Violeta Parra.

Por su parte, si bien la filmación de Mimbre tuvo lugar en 1957, la postproducción fue bastante complicada y varias fuentes revelan que el sonido tardó en finalizarse. Una nota de prensa respecto a las primeras actividades del Centro Experimental señaló en mayo de 1958 que Mimbre estaba aún en postproducción y anunciaba que la película contaría con música compuesta por Gustavo Becerra e interpretada en guitarra por Arturo González, un reconocido guitarrista clásico en esos años en Chile (Ercilla, 14 mayo 1958). Esto revela que, hasta esa fecha, la cinta no estaba aún terminada y ni siquiera se había definido quién compondría la música. Al parecer había una inquietud de utilizar guitarra, pero finalmente no sería con Becerra ni González. Semanas después, cuando el documentalista escocés John Grierson visitó Chile en junio de 1958, el Centro organizó una muestra que incluyó una

${ }^{4}$ Para un estudio en profundidad de la música en el cine chileno ver Farías (2021). 
versión sin sonido de Mimbre (Horta 2015, 8). Todo sugiere que la película seguía sin tener música. En agosto de 1959, una nueva muestra organizada por el Centro incluyó Mimbre en el programa junto a otras películas de Sergio Bravo. En una nota de prensa del evento se menciona el trabajo de Violeta Parra, pero no por Mimbre sino por Trilla (Sergio Bravo, 1959) (Ecran 1490, 18 agosto 1959, 27). Esto sugiere que la primera colaboración entre Bravo y Parra podría no ser Mimbre sino Trilla, que también incluye algunas piezas experimentales en guitarra. Es probable que la compositora creara la música de Mimbre durante el mismo periodo en algún punto durante 1959 como de hecho señala la biografía escrita por su hija Isabel, que sitúa la colaboración de Parra y Bravo en el año 1959 (Parra 1985, 200) al igual que una biografía más reciente (Štambuk y Bravo 2011, 180).

Con todo, la primera mención de una muestra de Mimbre que consignara a Parra es recién de diciembre de 1959 cuando la cinta fue incluida en un festival de documentales organizado por la Universidad de Chile (Ecran 1509, 29 diciembre 1959, 15). Toda esta información demuestra que no es hasta la segunda mitad de 1959 que la música fue compuesta y por tanto la película finalizada. Por esta razón, se propone en este artículo utilizar el formato 1957-1959 para datarla.

Esta discusión respecto a las fechas precisas puede parecer irrelevante, pero, lejos de eso, representa un cuestionamiento significativo a la historiografía. Al fechar la cinta en 1957 se ha periodizado el cine chileno ubicando a Mimbre como un primer hito del cine experimental nacional y como puntapié del desarrollo del Nuevo Cine Chileno. Claudia Aravena e Iván Pinto (2018) por ejemplo consideran Mimbre y 1957 como el nacimiento del cine y video experimental en Chile. De modo similar, Claudio Guerrero y Alekos Vuskovic (2018) marcan ese año y la cinta de Bravo como el origen del Nuevo Cine Chileno.

La insistencia en datar la película en 1957 implica una profunda invisibilización del trabajo de Parra pues se asume que la fecha de creación de la obra es la de la filmación de las imágenes, dejando lo musical como un aspecto accesorio que no amerita considerarse para entender la cinta como terminada. Un hecho paradójico si consideramos que prácticamente todas las pesquisas sobre cine chileno que mencionan a Mimbre lo hacen destacando la composición de Parra. A su vez, el hecho de que la película fuera finalizada en 1959 la vuelve contemporánea de un grupo de películas producidas por el Centro Experimental como Día de Organillos, Trilla e Imágenes antárticas 
desestabilizando la noción de una sola "obra maestra” que se adelantó a su tiempo como gran parte de la historiografía implícitamente sugiere.

Otro aspecto que permanece sin dilucidar es la supuesta narración que habría tenido Mimbre. Una nota de prensa acredita al locutor Darío Aliaga como narrador y al escritor Sergio Ampuero como autor del texto y se queja respecto a la "confusa locución" de la cinta (Ecran 1490, 18 agosto 1959, 27). ${ }^{5}$ Asimismo, en su fundacional libro sobre el Nuevo Cine Latinoamericano, Zuzana Pick confirma la existencia de una narración que describe como "fastidiosamente redundante" (1993, 111). Años más tarde, Pick menciona nuevamente la narración y añade que el texto pertenece a Sergio Ampuero, a quien describe como un escritor amigo de Bravo (2003, 287). En una comunicación personal más reciente, Pick señaló que vio Mimbre en París a comienzos de los ochenta en una muestra organizada por el propio Bravo que vivía allí. Sus escritos al respecto se basan en este visionado. No obstante, la investigadora no recordaba mayores detalles pues habían pasado más de cuarenta años. ${ }^{6}$ La versión de Mimbre que se preserva, y que fuera restaurada en 2006, no incluye narración y las investigaciones más recientes tampoco mencionan su existencia. Muy por el contrario, se tiende a afirmar que la música de Violeta Parra es el único elemento sonoro del filme. La decisión de remover la narración es significativa pues con esto la película se aleja de una estética clásica en favor de un estilo más experimental. A su vez, esto realza el rol de la música que, tal como se ha afirmado, domina totalmente la banda sonora.

El director Sergio Bravo ha sido reacio a la digitalización y a dar libre acceso a sus películas. Si bien cuatro cintas suyas se restauraron en 2006, su visionado solo puede realizarse acudiendo de manera presencial a la Cineteca Nacional. No obstante, dos de sus películas están disponibles en Youtube por gentileza de un usuario anónimo y seguramente sin la autorización de Bravo. El estudio de esos documentales, hoy consideradas cintas fundacionales del llamado Nuevo Cine Chileno y del cine experimental latinoamericano, está mediado por este hecho azaroso. Esta versión restaurada de Mimbre, que es la que se conserva también en la Cineteca, no incluye narración

\footnotetext{
${ }^{5}$ Aliaga trabajó como narrador para varios documentales y películas institucionales de aquellos años. Él y Ampuero fueron colaboradores habituales de Bravo y del Centro Experimental.

${ }^{6}$ Entrevista a Zuzana Pick realizada por el autor el 9 de agosto de 2018 vía correo electrónico.
} 
y a la fecha no ha sido posible dar con una copia que la incluya. Resulta curioso que quienes han escrito acerca del Centro de Cine Experimental y de Mimbre no notaran o no les pareciera relevante que en su origen la cinta tuvo un narrador como consignó la prensa y que así circuló al menos hasta los años 80 considerando aquella muestra en París donde Zuzana Pick la vio.

\section{La batalla de Chile: buscando narrador}

Considerado por muchos como el mejor documental de la historia de Chile, La batalla de Chile continúa siendo exhibido regularmente alrededor del mundo a casi cincuenta años del estreno de su primera parte. ${ }^{7}$ La obra ha sido objeto de innumerables estudios que han analizado su producción (Ortega 2003; Aguiar 2016), sus operaciones textuales (Lopez 1990) su condición de documento histórico (Arnal 2015), su tratamiento de la realidad (Scherbovsky 2016) y su factura visual (Borunda 2018). Aunque no existe tanto misterio como en el caso de Mimbre, el célebre documental en tres partes también ha sido objeto de algunos cambios significativos en el plano sonoro.

Como ha sido profusamente documentado, el equipo realizador vivió una situación apremiante luego del golpe de Estado y sus esfuerzos estuvieron dirigidos a poder sacar el material filmado del país (Guzmán 2012) Una vez logrado esto, el director Patricio Guzmán se estableció en Cuba junto con el montajista Pedro Chaskel para dar forma a la película con el apoyo del Instituto Cubano del Arte e Industria Cinematográficos ICAIC que les facilitó una sala de montaje y apoyo técnico. Allí se incluyó una narración grabada por el locutor cubano Pedro Luis Fernández Vila, quien también cumplía esas labores para el noticiero ICAIC (Álvarez 2012, 322). El locutor trabajó en la famosa Radio Reloj y se desempeñó como narrador en varios documentales cubanos de los años setenta y ochenta como Victoria en Ogaden (Romano Splinter, 1978), Símbolo del deber (Roberto Velázquez, 1980), FAPLA-FAR. Maniobra (Miguel Ángel Oro, 1981) y Propiedad de la personalidad (Pedro Pérez, 1984) producidos por los Estudios

\footnotetext{
${ }^{7}$ En 2016, La batalla de Chile fue considerada entre las cinco mejores películas del cine chileno y como el mejor documental en la encuesta realizada por CineChile.cl (Morales 2016). Asimismo, en 2020 la revista The New Yorker la incluyó entre las 62 más influyentes de la historia del documental a nivel mundial (Brody 2020).
} 
Cinematográficos y de Televisión de las Fuerzas Armadas Revolucionarias ECTV-FAR.

El tono y estilo de la narración responde en buena medida a lo que se conoce como "la voz de dios", es decir el modelo clásico del narrador en el documental en que una voz masculina de tono grave y profundo articula un relato omnisciente respecto a lo que vemos en pantalla guiando nuestra interpretación (Wolfe 1997, 149-151). Con esa voz, la película fue estrenada y circuló hasta mediados de los años noventa cuando Patricio Guzmán emprendió un proceso de restauración de la cinta con el apoyo de la Fundación MacArthur y aprovechó para realizar algunos cambios tanto en el texto narrado como en su interpretación. Según Jorge Ruffinelli (2008) las modificaciones en el texto buscaban depurar el léxico de los años setenta para poder comunicar mejor el contenido al público joven de los noventa. Así, por ejemplo, expresiones como "burguesía" o "derecha" fueron reemplazadas por "clases privilegiadas" y "oposición” respectivamente mientras que "la Casa Blanca" reemplazó a "imperialismo". ${ }^{8}$ Junto con los cambios en el texto se recurrió al locutor Abilio Fernández cuya voz grave, profunda y de marcado acento español dio un nuevo tono a la narración. Fernández había trabajado desde los años setenta en la Radio Nacional de España y más adelante en múltiples tareas asociadas a la voz como narraciones de cine, locuciones de publicidad y doblaje. ${ }^{9} \mathrm{Su}$ voz para La batalla de Chile continúa el estilo de "voz de dios" acentuado por su timbre grave y las cualidades expresivas asociadas con la locución profesional.

Ya a mediados de los 2000, Guzmán concibió un nuevo cambio de narrador, pero esta vez no contrató a un locutor profesional como había hecho anteriormente, sino que la interpretó él mismo. La fecha precisa del cambio no está del todo clara, aunque en una entrevista, el director proponía como fecha tentativa del cambio el 2005 (en Scherbovsky 2017). El hecho es que, en la edición en DVD del documental publicada en 2009, la voz del narrador era ya la del propio Guzmán. ${ }^{10}$ Algunos años después, cuando se encontraba presentando

\footnotetext{
${ }^{8}$ Más detalles en la sección "El narrador" correspondiente al capítulo de La batalla de Chile en Ruffinelli (2008).

${ }^{9}$ De acuerdo con la base de datos www.eldoblaje.com Abilio Fernández trabajó en 321 producciones entre 1970 y 2001 incluyendo doblaje de películas, locuciones publicitarias y narraciones.

${ }^{10}$ Para más información sobre la publicación en formato DVD ver González (2009).
} 
la película en Chile fue consultado por qué versión estaba exhibiendo, a lo que el director respondió:

Hay muchas versiones: cubana, española, francesa, inglesa, polaca, italiana, pero el texto es el mismo. $\mathrm{Y}$ en una versión que yo hice última yo quité un poco la palabra "fascismo", de la que abusaba mucho. Y abusaba mucho de la palabra imperialismo. Lo cambié por "Casa blanca", "Gobierno de Washington”; es lo mismo... Cambié 25 palabras. No es nada (en Pinto 2013).

El comentario alude a las versiones que se hicieron en otros idiomas como la narrada en inglés por una mujer, pues en los años setenta y ochenta todavía era común doblar las narraciones. ${ }^{11}$ Más recientemente esta práctica ha caído en desuso privilegiando el uso de subtítulos justamente como un modo de conservar y apreciar la narración original. Al mismo tiempo, el director comenta los cambios en el texto, pero no del narrador. Consultado al respecto, Guzmán parece un tanto molesto. Enfatiza que "a la película no se le cambió la voz" sino que se cambiaron palabras que "no pasaron de veinticinco a treinta". De igual modo, cuando se le pregunta si cree que utilizar su propia voz implica una diferencia para la audiencia, sostiene que no y añade que "si está bien narrada por otro, pasa igual. Es cuestión de calidad, de expresión" (en Scherbovsky 2016, 121).

Entendiendo que los directores son libres de hacer lo que se les plazca con sus películas y respetando la opinión del director, los cambios en el narrador resultan bastante más significativos de lo que considera Guzmán y ameritan por tanto una reflexión. Las transformaciones a nivel textual merecerían en sí mismas un análisis. Como apunta Scherbovsky, la sustitución de palabras como "revolución", "imperialismo" y "fascismo":

respondieron a la configuración de una época diferente que ya no estaba caracterizada por el desarrollo de procesos revolucionarios en América Latina sino por las consecuencias sociales/políticas/económicas que generaron las sucesivas y traumáticas dictaduras militares en el continente y por la implementación de un modelo societal neoliberal $(2016,122)$.

${ }^{11}$ Esta versión en inglés es con la que trabaja la investigadora Ana M. López (1990, 280). 
Ruffinelli (2008) sostiene que el léxico de la primera versión resultaba problemático porque "se trataba de un lenguaje de barricada, de lucha ideológica, cargado semánticamente con significaciones elementales" mientras que la segunda versión "amortigua" el lenguaje, aunque en lo sustancial no modifica su contenido, sino que lo complejiza. No obstante, no se busca aquí analizar el texto mismo sino reflexionar sobre la cuestión sonora. Qué significados promueven estas voces y por qué se debieran considerar los cambios de narrador en el estudio de $L a$ batalla de Chile.

\section{Las voces de La batalla}

Como sugiere Jacob Smith las voces revelan nuestros roles sociales y a su vez están profundamente ligadas a nuestros cuerpos y nuestro sentido de identidad $(2008,3)$. En esta misma línea, Philip Tagg utiliza la noción de vocal persona entendida como cualquier aspecto de la personalidad mostrado o percibido por otros a través del habla o el canto y añade que parámetros como el timbre, la entonación, el volumen, la dicción, la velocidad entre otros ofrecen atisbos sobre nuestra identidad, emociones y sentimientos (2012, 344-346). Estas nociones de identidad resultarán clave al momento de escuchar las narraciones de La batalla de Chile y considerar las diferencias y particularidades que éstas promueven.

En cuanto a la voz en el cine, Claudia Gorbman enfatiza que ésta no es un simple vehículo para la información textual y destaca sus particularidades sonoras como acento, tono, timbre y ritmo $(2014,8)$. Respecto al timbre y tono, en La batalla de Chile tanto el narrador cubano como el español tienen voces graves y trabajadas. Son ambos locutores profesionales con experiencia y cuyas voces están también asociadas a las variadas producciones en las que trabajaron. La voz de Guzmán no comparte esas características. Aunque no es particularmente aguda, no es una voz trabajada y mantiene por tanto un carácter más informal, menos distanciado que el de los profesionales. A su vez, llaman la atención las cualidades sonoras de la voz del director. Recordemos que la grabación se realizó cuando éste tenía más de sesenta años y por tanto es el timbre de un hombre mayor a diferencia de los anteriores narradores. Impresas en la película, esas características tímbricas son altamente simbólicas porque representan 
el paso del tiempo y la experiencia vivida por el director comentando las imágenes del pasado.

Las voces de cada narrador a su vez constituyen una adscripción geográfica determinada. En palabras de Shilpa Davé el acento permite la identificación del origen nacional o regional de una persona sin necesidad de verla $(2013,2)$. Los acentos nos remiten a países específicos y con ellos se articulan imaginarios y asociaciones que trascienden los contenidos que expresan a nivel textual. Por su parte, Hamid Naficy desarrolla el concepto de cine de acentos o accented cinema para designar un diverso tipo de producción fílmica en contextos de diáspora o exilio donde aparece con fuerza el acento como una marca distintiva a nivel sonoro de un tipo de discurso y de un lugar de enunciación. El autor sugiere que "si el cine dominante es considerado universal y sin acento" este cine con acento expresa la condición desterritorializada de sus realizadores $(2001,4)$.

En esta línea, la voz del cubano Fernández Vila actúa como un anclaje que vincula explícitamente la película a Cuba, el lugar del exilio de sus realizadores. Podemos escuchar en ella el acento cubano inconfundible del locutor y así en la conjunción de las voces chilenas que se escuchan a lo largo de la cinta y la del narrador, se hace evidente la condición de exilio de esta producción. El reemplazo de su voz, por tanto, implica un alejamiento simbólico de Cuba pues, más allá de algunos créditos, no hay nada en la cinta que la conecte directamente con dicho país. En el Chile de la transición de comienzos de los noventa, el imaginario en torno a la isla estaba profundamente marcado por la satanización del régimen cubano por parte de la dictadura militar y el intento de la izquierda renovada por desmarcarse del socialismo que parecía haber demostrado su inviabilidad. A su vez, la situación económica cubana era particularmente dura pues se vivían los años del llamado "periodo especial” luego de la caída del bloque socialista (Bell Lara et. al., 2017). Por estas razones, el vínculo con Cuba podía no ser conveniente para la exhibición de la película que, recordemos, no había tenido un estreno oficial en Chile y solo había circulado en forma clandestina hasta entonces. La segunda narración, realizada por el locutor español venía a solucionar el problema, desmarcando el filme de su asociación con la isla. El cambio es bastante simbólico a nivel sonoro pues el acento español aleja el relato de la esfera latinoamericana y la ubica en España que en los noventa vivía tiempos de prosperidad pues había salido de una larga dictadura y experimentaba la consolidación de su sistema 
democrático. Al mismo tiempo, este acento propiciaba una asociación con el mundo de la información pues se emparentaba con reportajes y documentales divulgativos realizados o doblados al español que transmitía la televisión chilena en los años noventa.

El reemplazo de los narradores externos por la voz de Guzmán va a romper la distancia y el aura de objetividad que promueven estos narradores distanciados. A diferencia del narrador omnisciente, Guzmán hace parte de la acción pues lo vemos en pantalla y lo escuchamos dirigirse al camarógrafo Jorge Müller o entrevistar a personas. A pesar de situarse en un lugar y tiempo distintos no es una voz desconocida. Grabada desde un presente indefinido, su voz articula una visita a su propio pasado en el que le vemos joven y barbudo. Asimismo, es una voz fácilmente identificable para el público en la medida que hoy el director es una persona reconocida que ha dado innumerables entrevistas y que suele presentar sus películas. Incluso para un público que no lo conoce el hecho de escucharlo decir algunas palabras antes de la proyección basta para luego reconocer esa voz como la del narrador.

La narración de Guzmán lo ubica como un protagonista de la historia y convierte la cinta en una suerte de relato en primera persona. Aunque el estilo de La batalla de Chile es bastante distinto, este cambio emparenta en alguna medida la cinta con el documental autobiográfico. Valeria De los Ríos y Catalina Donoso distinguen una "clara impronta autobiográfica” en el documental contemporáneo chileno en que se abandonan las aspiraciones de objetividad para acercarse a la producción de actos performativos donde lo central es la "voz propia, íntima" (2016, 207). En esta misma línea, Constanza Vergara y Michelle Bossy analizan un corpus de documentales autobiográficos y sostienen que en una gran proporción éstos "llevan a cabo un trabajo de memoria" vinculando "el recuerdo individual y la experiencia colectiva" (2010, 9). Aunque La batalla de Chile esté lejos de esta estética y pueda ponerse incluso en sus antípodas, la narración de Guzmán la acerca a estos modos de representación.

Ignacio Rodríguez (2010) analiza el cine de Patricio Guzmán para constatar un giro subjetivo en el documental político latinoamericano mediante una comparación de La batalla de Chile con dos de sus producciones posteriores: Chile, la memoria obstinada (1997) y Salvador Allende (2004). El autor distingue un abandono de las aspiraciones de objetividad para acercarse a formas más subjetivas en las que se cruzan 
tanto experiencias de "actores sociales" específicos como del mismo realizador. Se rompe así con la propuesta de La batalla de Chile, que Rodríguez describe como "un clásico film expositivo" con una narración "impersonal y anónima que relata los hechos de un modo distanciado" (2010, 4). Aunque no lo menciona, probablemente trabaja con la versión de los años noventa con narrador español que es la que más circuló desde su elaboración en los años noventa hasta fines de los 2000. Por contrapartida, Rodríguez ofrece como ejemplo Chile, la memoria obstinada, donde Guzmán asume el rol de narrador y con esto "el estilo distanciado de la narración en tercera persona cede lugar al relato personal” $(2010,5)$. Siguiendo esta propuesta es posible pensar la inclusión de la voz de Guzmán en La batalla de Chile justamente como parte de ese giro subjetivo.

A través de la voz, escuchamos a Guzmán como el testigo privilegiado de hechos que cincuenta años después resultan casi inverosímiles. Para quienes nacieron después de que la película se produjo, el Chile de $L a$ batalla de Chile puede parecer sacado de una ficción y es la voz de su director la que nos guía por ese pasado increíble para dar testimonio de que aquello fue cierto. Bill Nichols sostiene que el cine documental se ha basado en gran medida en la palabra hablada y que la narración suele tener "un halo de autenticidad" pues nos invita a asumir como cierto lo que se nos cuenta $(1997,51)$. En el caso de la narración de Guzmán, hay una capa más de autenticidad pues el director fue testigo de los hechos que narra. A diferencia de los narradores cubano y español cuyo conocimiento de los hechos que presenta el documental puede ponerse fácilmente en tela de juicio, la voz de Guzmán funciona como un testimonio en primera persona alejándose así del modelo de narrador clásico.

Tal como en el caso de Mimbre, Guzmán ha promovido la conservación de la última versión de la película, es decir la que incluye su propia voz. ${ }^{12}$ Hoy en día la copia con narrador español solamente circula en Youtube y con una calidad bastante baja. La versión con narrador cubano es prácticamente imposible de encontrar y solo un breve fragmento está disponible en Youtube con una calidad aún peor. En la

\footnotetext{
${ }^{12}$ A 46 años del estreno de la primera parte, el documental fue exhibido por primera vez en la televisión chilena los días 10, 11 y 12 de septiembre de 2021 por el canal La Red. La versión exhibida fue justamente la que tiene a Guzmán como narrador.
} 
Cineteca Nacional la única copia que se conserva es la que donara Guzmán con su propia voz lo que demuestra el claro intento por dejar esa versión como la definitiva en desmedro de las anteriores. Sin embargo, ante cambios tan profundos como los mencionados, cabe preguntarse si es posible pensar en La batalla de Chile como una única película o sería necesario tener en cuenta estas transformaciones y consignarlas en el entendimiento de una obra que ha sido fundamental para la historia del cine chileno y latinoamericano.

\section{Conclusiones}

Tanto en Mimbre como en La batalla de Chile los cambios en la narración contribuyen a un alejamiento de formas a menudo criticadas desde el mundo del documental de autor emparentándolas con estéticas más experimentales o cercanas al cine de arte. La inclusión de la voz de Guzmán en La batalla de Chile no solo marca distancia con el modelo de narración expositiva, sino que lo acerca a un tipo de cine donde la subjetividad juega un rol preponderante. Asimismo, con este cambio la película se emparenta con las producciones más recientes del director formando un corpus más homogéneo. De igual modo, la remoción del narrador en Mimbre la posiciona aún más dentro de los preceptos del cine experimental que celebra la exploración de los aspectos visuales y sonoros en desmedro de la palabra hablada. Al mismo tiempo, en ausencia de la voz, la música experimental de Violeta Parra adquiere una posición preponderante en la esfera sonora subrayando el carácter vanguardista del film. En cuanto a Mimbre y la música de Violeta Parra llama la atención que, pese a la diversidad de estudios acerca de la cinta y de la compositora, la cuestión de las fechas siguiera siendo un misterio. Este tipo de información puede considerarse secundaria, pero cobra valor en la medida en que contribuye a construir modos de entender la historia del cine privilegiando retóricas de genialidad y unicidad.

La restauración y conversión a digital en ambos casos no ha sido simplemente el paso de un formato a otro sino una oportunidad para llevar a cabo procesos de reelaboración. La supresión de la narración en Mimbre, así como los dos cambios de narrador en La batalla de Chile constituyen transformaciones significativas que ameritan ser consideradas al momento de estudiar las cintas. Por su parte, el acceso a estas fuentes no es un hecho exento de problemas y está mediado por 
circunstancias y decisiones que visibilizan determinadas versiones de las películas mientras que otras quedan invisibilizadas.

En términos metodológicos estos dos casos vienen a ilustrar una serie de problemáticas que enfrenta el estudio del cine chileno y que fácilmente podemos trasladar a otras realidades. Más allá de su especificidad, lo que podemos extraer de ellos es cómo la consideración de aspectos sonoros que hasta hoy siguen siendo marginales en el estudio del cine latinoamericano, pueden entregarnos información y perspectivas novedosas para pensar desde otro lugar las historias contadas.

\section{Referencias}

Albornoz, Ignacio. 2020. "Archivos fílmicos en línea: apuntes en torno al acervo universitario chileno". Contratexto 34: 177-204. https://doi.org/10.26439/contratexto2020.n034.4872

Álvarez, Mayra. 2012. El noticiero ICAIC y sus voces. La Habana: Ediciones La Memoria.

Aguiar, Carolina Amaral de. 2016. "Chris Marker y la SLON en La batalla de Chile". En Memorias y representaciones en el cine chileno y latinoamericano, editado por Mónica Villaroel, 49-57. Santiago: LOM.

Aravena, Claudia y Pinto, Iván. 2018. Visiones laterales: Cine y video experimental en Chile (1957-2017). Santiago: Metales Pesados.

Arnal, Ariel. 2015. "La construcción de la memoria y la consciencia histórica en La batalla de Chile”. Tesis doctoral. Tarragona: Universitat Rovira I Virgili.

Bell Lara, José, Caram, Tania, Kruijt, Dirk, y López, Delia. 2017. Cuba: Periodo Especial. La Habana: Editorial UH.

Borunda, Stephen. 2018. "Political Revelations in Detail: The Close-Up in Patricio Guzmán's The Battle of Chile”. Film Matters 9 (2): 6983.

Brody, Richard. 2020. "Sixty-two Films That Shaped the Art of Documentary Filmmaking”. https://www.newyorker.com/culture/the-front-row/sixty-twofilms-that-shaped-the-art-of-documentary-filmmaking. Acceso 18 octubre 2021. 
Corro, Pablo, Alberdi, Maite, Larraín, Carolina, y Van Diest, Camila. 2007. Teorías del cine documental chileno 1957-1973. Santiago: Pontificia Universidad Católica.

Cortínez, Verónica y Engelbert, Manfred. 2014. Evolución en libertad: el cine chileno de fines de los sesenta. Santiago: Cuarto Propio.

Cuarterolo, Andrea. 2017. "El archivo en la época de su reproductibilidad técnica. Recursos digitales para el estudio del cine silente latinoamericano". Vivomatografías 3: 416-447. http://hdl.handle.net/11336/74050

Davé, Shilpa. 2013. Indian Accents: Brown Voice and Racial Performance in American Television and Film. Baltimore: University of Illinois Press.

De los Ríos, Valeria y Donoso, Catalina. 2016. "Apuntes sobre el documental chileno contemporáneo”. Revista Nuestra América 10, 207-219.

Farías, Martín. 2021. Identidad y política en la música del cine chileno 1939-1973. Santiago: Ariadna Ediciones. https://doi.org/10.26448/ae9789566095187.4

González, Gabriela. 2009. "La Batalla de Chile se presenta en formato DVD”. $\quad$ https://cinechile.cl/noticias/la-batalla-de-chile-sepresenta-en-formato-dvd/. Acceso 18 octubre 2021.

Gorbman, Claudia. 2014. “The Master's Voice”. Film Quarterly 68 (2): 8-21. https://doi.org/10.1525/fq.2014.68.2.8

Guerrero, Claudio, y Vuskovic, Alekos. 2018. La música del Nuevo Cine Chileno. Santiago: Cuarto Propio.

Guzmán, Patricio. 2012. "Lo que debo a Chris Marker". laFuga 14. https://lafuga.cl/lo-que-debo-a-chris-marker/556. Acceso 18 octubre 2021.

Horta, Luis. 2015. "La subversión de las imágenes: la producción de cortos documentales de la Universidad de Chile y su rol en la renovación del cine nacional 1960-1965". Imagofagia 12: 1-23.

Lopez, Ana M. 1990. "The Battle of Chile: Documentary, Political Process, and Representation”. En The Social Documentary in Latin America, editado por Julianne Burton, 267-287. Pittsburgh: University of Pittsburgh Press. 
Morales, Marcelo. 2016. "Las 50 mejores películas chilenas de todos los tiempos". http://cinechile.cl/criticas-y-estudios/las-50-mejorespeliculas-chilenas-de-todos-los-tiempos/. Acceso 18 octubre 2021.

Naficy, Hamid. 2001. An Accented Cinema: Exilic and Diasporic Filmmaking. Princeton; Oxford: Princeton University Press.

Navitski, Rielle. 2014. "Reconsidering the Archive: Digitization and Latin American Film Historiography". Cinema Journal 54 (1): 121-28.

Nichols, Bill. 1997. La Representación de la Realidad: Cuestiones y Conceptos Sobre el Documental. Barcelona: Paidos.

Ortega, María Luisa. 2003. "La batalla de Chile. The Battle of Chile". En The Cinema of Latin America, editado por Alberto Elena y Marina Díaz López, 151-159. Londres: Wallflower Press.

Parra, Isabel. 1985. El libro mayor de Violeta Parra. Madrid: Michay.

Pick, Zuzana. 1993. The New Latin American Cinema. A continental project. Texas: University of Texas Press.

-_- 2003. "Mimbre”. En Cine documental en América Latina, editado por Paulo Antonio Paranaguá, 287-288. Madrid: Cátedra.

Pinto, Iván. 2013. “Entrevista a Patricio Guzmán”. El Ángel Exterminador 22. http://elangelexterminador.com.ar/articulosnro.22/guzman.htm 1. Acceso 18 octubre 2021

Rodríguez, Ignacio. 2010. "Giro subjetivo en el documental político latinoamericano: el caso de Patricio Guzmán.” Imagofagia 2: 1-21.

Ruffinelli, Jorge. 2008. El Cine De Patricio Guzmán. Santiago: Uqbar. Versión digital sin número de página, disponible en https://www.bpdigital.cl. Acceso 18 octubre 2021.

Štambuk, Patricia y Bravo, Patricia. 2011. Violeta Parra. El canto de todos. Santiago: Pehuén.

Scherbovsky, Natacha. 2016. "Usos y estrategias de lo real en la construcción del cine revolucionario de Patricio Guzmán. El caso del documental La batalla de Chile". Tesis de Maestría. Quito: Facultad Latinoamericana de Ciencias Sociales. 
—_—. 2017. "La Batalla de Chile: acción, movimiento, lucha de clases y ocaso de una revolución II”. https://latinta.com.ar/2017/05/labatalla-de-chile-accion-movimiento-lucha-de-clases-y-ocaso-deuna-revolucion-ii/. Acceso 18 octubre 2021.

Smith, Jacob. 2008. Vocal Tracks. Performance and Sound Media. Berkeley; Los Angeles; Londres: University of California Press.

Tagg, Philip. 2012. Music's Meanings: a modern musicology for nonmusos. Nueva York; Huddersfield: Mass Media Music Scholars' Press.

Vergara, Constanza y Bossy, Michelle. 2010. Documentales autobiográficos chilenos. Santiago: Autoedición.

Wolfe, Charles. 1997. "Historicising the 'Voice of God': The Place of Vocal Narration in Classical Documentary”. Film History 9 (2): 149-67.

\section{Filmografia}

Chile, la memoria obstinada [documental, DVD] Dir. Patricio Guzmán. Canadá, Chile, Francia. 1997. 59 mins.

El cantor de jazz [ficción, DVD] Dir. Alan Crosland. Estados Unidos. 1927. 89 mins.

El derecho al descanso [documental, online] Dir. Adolfo Silva. Chile. 1971. mins. www.cinetecavirtual.uchile.cl/cineteca/index.php/Detail/object s/2480. Acceso 18 octubre 2021.

Escuela Santa María de Iquique 1907. [documental, online] Dir. Claudio Sapiaín. Chile. $\quad 1970 . \quad 24$ mins. http://www.cinetecavirtual.uchile.cl/cineteca/index.php/Detail Lobjects/2359. Acceso 18 octubre 2021.

FAPLA-FAR. Maniobra [documental, 35mm] Dir. Miguel Ángel Oro. Cuba. 1981. 27 mins.

Imágenes antárticas [documental, 16mm] Dir. Emilio Vicens y Sergio Bravo. Chile. 1957-1959. 17 mins.

La batalla de Chile [documental, DVD] Dir. Patricio Guzmán. Francia, Cuba, Chile. 1975, 1976 y 1979. 191 mins. (Narración de Patricio Guzmán) 
La batalla de Chile [documental, online] Dir. Patricio Guzmán. Francia, Cuba, Chile. 1975, 1976 y 1979. 191 mins. (Narración de Abilio Fernández). Parte 1: https://youtu.be/kUHsggUO0i4, Parte 2: https://youtu.be/9b gXhnZDEU, Parte 3: https://youtu.be/KSwStY5VfNw. Acceso 18 octubre 2021.

La batalla de Chile [documental, online] Dir. Patricio Guzmán. Francia, Cuba, Chile. 1975, 1976 y 1979. 191 mins. (Narración de Pedro Luis Fernández Vila). Parte 2 (fragmento) https://youtu.be/vloyZq74SBI. Acceso 18 octubre 2021.

Mimbre [documental, online] Dir. Sergio Bravo. Chile. 1957-1959. 10 mins. https://youtu.be/QLq78pOvtJo. Acceso 18 octubre 2021.

Propiedad de la personalidad [documental, 35mm] Dir. Pedro Pérez. Cuba. 1984. 18 mins

Salvador Allende [documental, DVD] Dir. Patricio Guzmán. Alemania, Bélgica, Chile, España, Francia, México. 2004. 100 mins.

Símbolo del deber [documental, 35mm] Dir. Roberto Velázquez. Cuba. 1980. 15 mins.

Trilla [documental, mp4] Dir. Sergio Bravo. Chile. 1959. 30 mins.

Victoria en Ogaden [documental, 35mm] Dir. Romano Splinter. Cuba. 1978. 18 mins.

\section{Música e Som no Cinema Chileno: Novas vozes para velhas histórias}

RESUMO Este artigo pondera sobre alguns problemas metodológicos e conceptuais que surgem no momento de estudar a música e o som no cinema chileno. Tais assuntos se situam no contexto de uma crescente digitalização de filmes e documentos que vem sendo levada a cabo nas últimas décadas, gerando uma série de mudanças no estudo do cinema. Com este fim, o artigo propõe uma análise de dois documentários icónicos da história do cinema no Chile: Mimbre (Sergio Bravo, 19571959) e La batalla de Chile (Patricio Guzmán, 1975-1979). Argumenta-se que o estudo da música e do som permite observar fenómenos ignorados e redefinir questões até agora negligenciadas pela historiografia.

PALAVRAS-CHAVE Cinema chileno; música para cinema; narrador, Mimbre; La batalla de Chile. 


\title{
Music and Sound in Chilean Cinema: New voices for old (hi)stories
}

\begin{abstract}
This article discusses a series of methodological and conceptual problems that emerge when studying music and sound in Chilean cinema. These issues appear in the context of the growing digitisation of films and documents during the last decades, which has entailed significant changes in the study of cinema. The analysis focuses on two iconic documentaries of Chilean film history: Mimbre (Wicker, Sergio Bravo, 1957-1959) y La batalla de Chile (The battle of Chile, Patricio Guzmán, 19751979). The article claims that the study of music and sound reveals problems that film scholars have largely ignored until now.
\end{abstract}

KEYWORDS Chilean cinema; film music; voice-over narrator; Mimbre; La batalla de Chile.

Recebido a 13-07-2021. Aceite para publicação a 11-10-2021.

aniki A Pesquisa Histórica no Cinema Latino-americano | Historical Research in Latin-American Cinema 